\title{
Um marco dos estudos dialetológicos: I Congresso Brasileiro de Dialectologia e Etnografia
}

Marisa Porto do Amaral ${ }^{*}$

FURG

Recebido em: 29/06/2019

Aceito em: 20/11/2019

Resumo: Este texto objetiva divulgar um evento muito importante para a história dos estudos dialetológicos no país: o I Congresso Brasileiro de Dialectologia e Etnografia, ocorrido em Porto Alegre, na então Universidade do Rio Grande do Sul, no ano de 1958, reunindo pesquisadores nacionais e estrangeiros para tratar, principalmente, da elaboração do futuro Atlas LinguísticoEtnográfico do Brasil. O referido Congresso ocorreu em um momento histórico em que se buscava identificar a língua portuguesa falada no Brasil: de um lado a busca por um padrão; de outro, a necessária descrição e registro da língua falada pelo povo, objeto primordial do futuro Atlas.

Palavras-chave: Dialetologia. Etnografia. Congresso brasileiro. Atlas linguístico.

Abstract: This text aims to divulge an event of utmost importance for the history of dialectical studies in the country: the First Brazilian Congress of Dialectology and Ethnography, held in Porto Alegre, at the then University of Rio Grande do Sul, in the year 1958, bringing together national and foreign researchers to deal mainly with the elaboration of the future LinguisticEthnographic Atlas of Brazil. The Congress tookplace at a historical moment in the language, in which it was sought to identify the Portuguese language spoken in Brazil.

Keywords: Dialectology. Ethnography. Brazilian congress. Linguistic atlas.

Resumen: Este texto tiene como objetivo divulgar um evento mui importante para la historia de los estúdios dialécticos em el país: el I Congreso Brasileño de Dialectologia y Etnografia, ucurrido em Porto Alegre, en la entonces Universidad de Rio Grande do Sul, en el año de 1958, reuniendo investigadores nacionales y extranjeros para tratar, principalmente, de la elaboración del futuro Atlas Lingüístico-Etnográfico de Brasil. El Congreso tuve lugar en un momento histórico em el que se trató de identificar el idioma português hablado en Brasil. Palabras-clave: Dialectologia. Etnografia. Congreso brasileño. Atlas linguístico. 


\section{Introdução}

Na segunda metade do século passado, mais precisamente nos anos 50, a cultura brasileira foi marcada por debates e polêmicas, entre os quais a questão da linguagem popular:

Indagava-se sobre sua legitimidade e sobre sua integração. Ou seja, fazia-se presente no cerne dos debates culturais uma polêmica em torno da língua dizendo respeito à diversidade linguística interna ao país. Nesse sentido, vale ressaltar que é nos anos 50 que ocorrem, paralelamente aos primeiros congressos de folclore, os primeiros congressos de língua falada e de dialetologia (MARIANI; MEDEIROS, 2007, p. 133).

As ideias nacionalistas, principalmente de Amadeu Amaral e Antenor Nascentes, na linguística, e Mário de Andrade e Oswald de Andrade, na literatura, fizeram-se presentes nos eventos que se seguiram:

- Congresso de Língua Nacional Cantada, em 1937 - São Paulo, que Mário de Andrade organizou e no qual Antenor Nascentes teve papel importante, ao influir nas deliberações sobre as normas de pronúncia aprovadas. O objetivo do congresso era estabelecer normas de como se deve cantar na língua do país.

- Congresso Brasileiro de Língua Vernácula, homenagem ao primeiro centenário de Rui Barbosa, em 1949, promovido pela Academia Brasileira de Letras. Grande parte dos trabalhos tratou da língua culta, apesar de algumas comunicações terem sido referentes à linguagem popular do Brasil.

- I Congresso de Língua Falada no Teatro, em 1956, onde foram apresentadas comunicações que muito interessavam à dialetologia brasileira. A ideia era a de estabelecer uma pronúncia única para o teatro.

- I Congresso Brasileiro de Dialectologia e Etnografia, em 1958, considerado um marco, de acordo com Castilho (1972-3, p. 126):

Os estudos dialetológicos no Brasil têm seu divisor de águas no período compreendido entre 1953 (fundação do Centro de Estudos de Dialetologia Brasileira', no Rio de Janeiro) e 1958 (I Congresso Brasileiro de Dialetologia e Etnografia, em Porto Alegre).

\footnotetext{
1 O Centro de Estudos a que Castilho se refere acima foi criado no Museu Nacional do Rio de Janeiro por Serafim da Silva Neto que objetivava criar uma "mentalidade dialetológica" no Brasil, dispondo-se a dar palestras e cursos por todo o território nacional para difundir a dialetologia brasileira. Infelizmente, em setembro de 2018, o Museu Nacional sofreu um incêndio devastador que tomou conta de quase todo o acervo construído em mais de duzentos anos.
} 
Enquanto nos três primeiros congressos predominava a busca por uma pronúncia padrão ou uma língua padrão que representasse a identidade nacional, no congresso de 1958, o que se almejava era registrar a diversidade linguística. E é esse último evento o tema do presente estudo. A base de dados de análise são os manuscritos dos Anais desse evento $^{2}$ que, até onde se sabe, não foram publicados.

Pereira (1995) coloca o Congresso dentro do primeiro período (1920 a 1963) 3 da fase que ela chama de descritiva, quando se manifesta um crescente interesse pela nossa realidade linguística:

(...) há um conflito, por vezes apaixonado, entre os seguidores de uma tradição lusitanizante e os adeptos da legitimação, em nível de norma, das inovações linguísticas nacionais, conflito que se acentua ao aproximar-se a data do primeiro centenário da nossa independência. Começaram então a surgir trabalhos fundamentais nas áreas da língua, da literatura, da etnografia e da história em busca de nossa identidade nacional (PEREIRA, 1995, p. 353).

No entanto, um dos dilemas que se apresentava era a extensão territorial do país: os $8.513 .844 \mathrm{~km}^{2}$ do Brasil agravavam as dificuldades de locomoção e estradas precárias, em muitas regiões. Além disso, o grau de preparação científica do pessoal e os recursos financeiros arrefeceram os ânimos para tão grande empreendimento.

Meio século passado da realização do Congresso, os manuscritos dos Anais analisados a seguir jogam luz a aspectos ainda inexplorados, na trajetória histórica dos estudos dialetológicos, no Brasil, de suma importância para a compreensão das concepções linguísticas vigentes nesse período.

\section{O Congresso}

Pode-se dizer que os preparativos para o Congresso tiveram seu início na primeira quinzena de agosto de 1957, quando Serafim da Silva Neto veio à Universidade do Rio Grande do Sul para ministrar um Curso de Dialetologia como preparação ao futuro

\footnotetext{
${ }^{2}$ Os manuscritos datados em 1958 encontram-se no Acervo dos Projetos ALERS / ALMA-H, coordenados pelo Prof. Cléo V. Altenhofen, que gentilmente cedeu cópia para análise, no âmbito de um Pós-Doutorado realizado por mim sob a sua supervisão, no Instituto de Letras da Universidade Federal do Rio Grande do Sul (UFRGS), em 2018.

${ }^{3}$ Este período vai do Dialeto Caipira, de Amadeu Amaral ao Atlas Prévio dos Falares Baianos, de Nelson Rossi.
} 
Congresso que iria se realizar nessa Universidade, no ano seguinte, conforme consta na sessão “Notícias e comentários” da Revista Brasileira de Filologia (1957, p.287):

\section{Recorte 1}

\section{UNIVERSIDADE DO RIO GRANDE DO SUL}

A convite da Faculdade de Filosofia, realizou-se de 1 a 15 de agosto p.p., um Curso de Dialectologia destinado a preparar o ambiente para um futuro Congresso de Dialectologia Brasileira a realizar-se em Pôrto Alegre. As aulas, que foram ministradas pelo Prof. Serafim da Silva Neto, obedeceram ao seguinte plano:

- Língua comum, dialetos e falares.

- O inquérito linguístico. Suas técnicas.

- Os atlas linguísticos: o que são e para que servem.

- Atlas e dicionários regionais.

- Os problemas do questionário.

Foi escolhida uma Comissão, constituída dos Professôres Elpídio Pais, Albino de Bem Veiga, Heinrich Bunse e Celso Pedro Luft, para elaborar um projeto de questionário linguístico destinado ao futuro Atlas do Sul do Brasil.

Fonte: revista brasileira de filologia (1958, p. 287)

\section{Finalidade e objetivos}

De acordo com a primeira circular, a finalidade e objetivos do Congresso se resumem, essencialmente:

a) na discussão dos aspectos científicos e metodológicos convenientes para a formação da mentalidade profissional e dos quadros brasileiros adequados a enfrentarem as pesquisas prévias do futuro Atlas Lingüístico-Etnográfico do Brasil;

b) na discussão de todos os aspectos e problemas conexos com a finalidade e objetivos do Congresso;

c) na organização de um Questionário Lingüístico-Etnográfico Brasileiro, que englobe os problemas fundamentais de coleta de dados dialectológicos e etnográficos brasileiros. 
Para isso, o temário do Congresso contemplou caracterização fonética, morfológica e sintática de modalidades linguísticas regionais do Brasil; estudos lexicográficos referentes às palavras de emprego regional ou palavras peculiares de línguas especiais; aspectos toponímicos e antroponímicos da realidade linguística brasileira; paremiologia e frases feitas; aspectos lúdicos e recreativos: aspectos e problemas metodológicos; aspectos específicos decorrentes de contatos sociais, particularmente dos elementos indígenas, negros e estrangeiros; aspectos da formação histórico-linguística do Brasil.

Durante a Semana da Pátria (de $1^{\circ}$ a 7 de setembro), em uma atividade intensa dos cerca de cem participantes, houve apresentação de trabalhos, mesas-redondas, discussões e debates de estudiosos do país e convidados do exterior que vieram contribuir com as suas experiências na grandiosa e problemática tarefa de preparar o Atlas Linguístico-Etnográfico do Brasil. Neste encontro a variação dialetal estava no centro das atenções dos pesquisadores, como podemos observar na figura a seguir.

Figura 1 - Reunião de especialistas da língua portuguesa no I Congresso de Dialetologia e Etnografia, em Porto Alegre (1o a 7 de setembro de 1958)

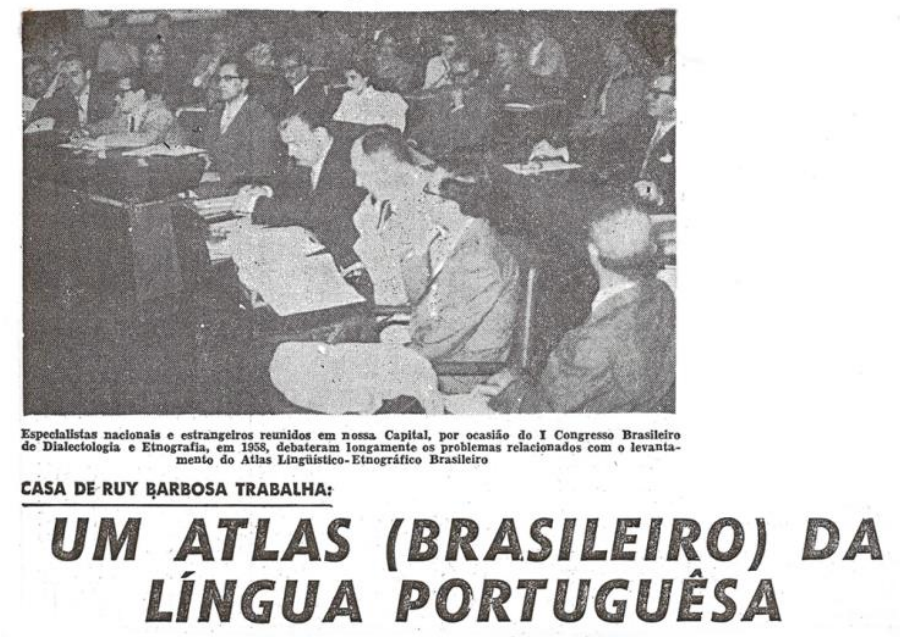

Fonte: Jornal Correio do Povo, 25/05/1960

A elaboração do Atlas Linguístico do Brasil era a tarefa principal da Comissão de Filologia do Centro de Pesquisas da Casa de Rui Barbosa, instituído no Governo Vargas, no Rio de Janeiro, de acordo com o decreto no 30.643, de 20 de março de 1952. Urgia, então, dar início a esse grande empreendimento. 
Em seu discurso de abertura, o Prof. Albino de Bem Veiga, presidente executivo do Congresso, no Salão de Atos da Universidade do Rio Grande do Sul, proferiu as seguintes palavras:

Desde que, em 1956, o Congresso de Língua Falada no Teatro escolheu (e segundo pude observar com entusiasmo) o Rio Grande para nêle realizar-se o I Congresso Brasileiro de Dialetologia e Etnografia, os senhores Ministro de Educação e Cultura, Prof. Clóvis Salgado e o Reitor da Universidade, Prof. Elyseu Paglioli, muito fizeram para tornar possível este conclave. (...) À gentileza da escolha vem somar-se outros fatores determinantes como a posição geográfica do Rio Grande: estado mais meridional e fronteiriço, voltado, por destinação histórica, aos trabalhos dialectológicos (BEM VEIGA, 1958, fl.1).

Aqui ele relembra que os primeiros estudos na área da Dialetologia devem-se primeiramente ao porto-alegrense Antônio Álvares Pereira Coruja com sua "Coleção de Vocábulos e Frases Usadas na Província do Rio Grande do Sul”, publicada em 1851-52, o qual já escrevera o primeiro "Compêndio de Gramática da Língua Nacional”, em 1835; a que seguiram-lhe outros como Apolinário Pôrto Alegre (1875), Beaurepaire Rohan (1888), Romaguera Corrêa (1889). E continua:

Quem no Rio Grande e no Brasil, porém, explicou vocábulos do linguajar sulrio-grandense foi José de Saldanha que em seu Diário Resumido e $\underline{\text { Histórico }}{ }^{4}$, escrito em 1786, apõe interessantíssimas notas elucidativas.

Hoje, as técnicas e métodos apregoados pela Geografia Linguística impõem novas tarefas.

Sabemos (e tem sido já numerosos os filósofos de responsabilidade que o tem manifestado), sabemos que a renovação da Filologia Portuguêsa está dependente dos atlas linguísticos (BEM VEIGA, 1958, fl.2).

Era evidente o interesse de todos os envolvidos em torno das soluções para o grande problema, pois consideravam a execução do Atlas o único caminho para uma política linguística nacional.

A elaboração do Atlas Linguístico e Etnográfico do Brasil espelhava, neste sentido, os sentimentos da época: "historicamente, era visto como uma tarefa patriótica que revelava a verdadeira face do Brasil; epistemologicamente, representava a renovação da Filologia Portuguesa" (ALTENHOFEN, 2011, p. 20).

\footnotetext{
${ }^{4}$ Grifo do autor.
} 


\section{Trabalhos apresentados}

Os estudiosos brasileiros e estrangeiros que participaram do referido Congresso tinham em comum o interesse pela diversidade dos estudos dialetológicos. E seguindo o temário já referido, faço um breve resumo das comunicações apresentadas no evento.

\section{1) Peculiaridades da Fala da Bahia - Edison Carneiro}

Esta comunicação trata da linguagem falada que caracteriza a população baiana, no caso, o som do $\mathrm{x}$, do $\mathrm{g}$ e do $t$, em quase todas as camadas sociais, como 'próchimo' (próximo) que, “ortoepicamente”, deveria pronunciar-se ss. "O g soa de modo singular apenas na palavra gente. Ora vale x (ch), ora $r$ forte: ô xente para ó gente, a rente sabia”. Ou se a palavra gente vem desacompanhada, o g pronuncia-se como dj, numa só emissão de voz: djente. $\mathrm{O}$ autor diz que é muito conhecida a pronúncia de muito: não somente se nasala o mui (mum), como o $t$ ganha um som chiante que semelha o do grupo $\underline{\mathrm{ch}}$ em espanhol, representado por t': oito (oit'o), leitura (lêt'ura).

\section{2) Uma forma dialectal num soneto de Alvarenga Peixoto - Rodrigues Lapa}

O autor inicia dizendo que está por fazer a colheita sistemática das formas populares no português do Brasil, existentes nos documentos do passado. Para isso, torna-se necessário um trabalho de equipe metódico, em que se confrontam constantemente com os resultados obtidos na investigação dos modernos falares locais, para apurar a sobrevivência, distribuição ou desaparecimento dessas antigas formas, já que com o rápido desenvolvimento técnico, a cultura tradicional tende a desaparecer. As fontes de que se vale são do século XVIII: a) Obras literárias: Cartas Chilenas, o soneto de Alvarenga Peixoto e outros; b) Prosa administrativa: as inquisições judiciais, sobretudo os Autos da Devassa da Inconfidência Mineira; c) Correspondência particular da segunda metade do século XVIII. A forma discutida é "adiente" por "adiante" no soneto, ou a palavra "semelhante", por duas vezes em ofício do Governador de Minas, Luís da Cunha Meneses, de 16/o3/1786.

3) A recolha de nomes populares de plantas: problemas e sugestões - Carlos Potsch 
O autor ressalta a importância da terminologia botânica, "o momento em que se cogita a elaboração de um Atlas Linguístico do Brasil.” E que a recolha apresenta grandes problemas, haja vista a riquíssima flora do país e a sua grande extensão territorial. Prevê para cada uma das regiões propostas, além de um questionário básico geral, um questionário especial, com referência à divisão fitogeográfica do Brasil, para trazer alguma contribuição à elaboração do questionário referente aos nomes populares das plantas.

4) Aspectos paremiológicos na obra de João Guimarães Rosa - Estella Glatt

A autora apresenta torneios verbais de um exemplário da obra de Guimarães Rosa. "Há que reconhecer em tais torneios verbais um acentuado cunho popular, não somente pela sua construção sintática, mas, e principalmente, pelos temas que abordam nas obras Sagarana, Corpo de Baile e Grande Sertão: Veredas”. O critério adotado é o do Dicionário da Real Academia Española para os refrãos, frases feitas, locuções e expressões adverbiais.

5) Formation des parles brésiliens: Dialectologie brésilienne et Histoire du Brésil - I. S. Revah

Na primeira parte, Revah faz uma descrição das palavras brasileiras da época moderna, tanto da língua mais natural das classes superiores como da língua popular das cidades e dos campos, nos seus sistemas morfológico e fonológico, concluindo que é através do domínio fonético que se pode estabelecer os limites da geografia linguística. Na segunda parte, faz uma tentativa de explicação histórica das características fonéticomorfológicas das palavras brasileiras.

6) Alguns aspectos fonético-comparativos do português do Brasil - Sylvio E. Elia

Para o autor, "também no campo da fonética se pode constatar a notável unidade da língua popular do Brasil.” A simplificação extrema se pode dar no domínio das formas (morfologia) da construção das frases (sintaxe) ou da enunciação oral (fonética). Exs.: os home_, as casa_(eu vô, tu vai, ele vai, nós vai, eles vai).

No final de sua comunicação, Sylvio Elia diz que "o que aí fica é um pequeno esforço de interpretação dos fatos fonéticos dos falares brasileiros. Uma explicação 
cientificamente satisfatória só poderá ser atingida depois de elaborado o Atlas Linguístico e Etnográfico do Brasil, cujo início de execução não poderá mais ser retardado" (grifo nosso).

\section{7) Questionário Linguístico-Etnográfico Brasileiro - Cândido Jucá (filho)}

Jucá apresenta um plano de trabalhos preparatórios para uma sondagem da realidade linguística brasileira. Mostra as perguntas que poderão ser feitas, elogia a possível colaboração do IBGE, da impressão de questionários que seriam enviados a todos os recantos da nação para consultar sobre o vocabulário das atividades locais, sobre a fonologia, a morfologia e a sintaxe de cada região.

8) Preliminares para um estudo das influências do português sobre os dialetos italianos em São Paulo - G. D. Leoni

Para tratar da influência do português, principalmente na pronúncia e no vocabulário dos dialetos italianos, o autor chama a atenção para a forma inovadora como conduz sua pesquisa, afastando-se, às vezes, dos métodos tradicionais. Teve particular cuidado ao compor os questionários. E as primeiras conclusões a que chegou são em relação à pronúncia.

9) Los cantes flamencos como poesia: su relación com el plantío y la endecha - Eugenio Asensio

Folclore poético que mostra a literatura culta e oral desde a antiguidade sobre o planto que fez surgir a playera (seguidilla gitana) no canto andaluz - los cantos flamencos. A endecha, ou verso de seis sílabas sempre serviu para chorar os defuntos ou as desgraças de um povo. Esse tipo de poesia oral "mantém vivo um estilo de sentimento e um modo de expressão que, sem perder o contato com o passado, renova-se e adaptase às novas exigências do tempo presente”.

10) Extension de isoglosas portuguesas em território uruguayo y el problema de la frontera entre el Português y el Español en el norte del Uruguay - José Pedro Rona

Interrelação entre o português e o espanhol no Rio da Prata (extensão de isoglossas portuguesas em território uruguaio e o problema de fronteira). O autor assinala três zonas: na primeira, o povo fala português, mas também castelhano; na 
segunda, é a do dialeto fronteiriço, que consiste em uma mistura de português e espanhol que, muitas vezes, torna-se ininteligível, tanto para os brasileiros quanto para os uruguaios; na terceira, fala-se castelhano com grande quantidade de portuguesismos, sobretudo no léxico, mas com a pronúncia do espanhol.

\section{1) Pesquisas dialetais na Universidade da Bahia - Nadya Maria Cruz de Andrade}

Elaboração e aplicação do primeiro questionário linguístico, em 1957, na Bahia. A autora diz que as pesquisas dialetais tiveram início com um exercício de campo realizado em Portão - Salvador, em 1957. Trata-se de um questionário experimental, elaborado com a ajuda de alunos, contendo 2.965 perguntas, inicialmente. Nesta comunicação, descreve as áreas investigadas no questionário e a metodologia aplicada.

12) Quadras populares no sertão baiano - Nelson Rossi

Quadras recolhidas em 1956, na Fazenda Lageado, entre as cidades de Uauá e Patamuté, no alto sertão do Nordeste da Bahia. Como não estava aparelhado para fazer a transcrição fonética, em algumas quadras pode-se notar a presença de variantes devido à força de repetições. Rossi espera que os especialistas não se interessem apenas por quadras inéditas, "mas a simples verificação da existência delas em um determinado ponto, talvez constitua subsídio não de todo inútil ao estudo de suas origens, transformação e propagação”.

13) Rio de Janeiro (para a história de um topônimo) - Celso Cunha

O autor refere que desde o início da língua portuguesa, a palavra rio designa um curso de água considerável, assim como ocorre nos outros idiomas. Mas, nesta comunicação ele examina "as possibilidades de atribuir-se acepção originária diversa ao termo rio em alguns topônimos do Brasil e da Costa d'África", com o fim de esclarecer a história do nome Rio de Janeiro, o qual "do designativo da Bahia de Guanabara, se estendeu à cidade, hoje capital do país, e a um estado da Federação”.

14) Subsídios para o estudo do falar carioca: a linguagem do turfe - Maria Amélia Pontes Vieira

Trata-se de um glossário que, além de termos e expressões próprias do turfe, contém outros vocábulos "da língua comum e pertencentes, inclusive, também àquele 
domínio". Segundo a autora, muitas expressões foram colhidas em conversas ouvidas entre jóqueis e tratadores, informações que tiveram, posteriormente, explicação e/ou retificação por técnicos consultados.

15) A terminologia da atafona no Rio Grande do Sul - Heinrich W. Bunse

Nesta comunicação, Bunse constata que, com a modernização da atividade de cultivo da mandioca, a atafona - lugar onde se fabrica a farinha da mandioca - parece “condenada à morte”, nas palavras do pesquisador. “(...) é difícil, já hoje em dia, encontrar uma atafona que não seja contaminada pelo progresso. Com isso, naturalmente, vai desaparecer também uma rica e tradicional terminologia, usada nas atafonas do Rio Grande do Sul". A terminologia apresentada é a mais primitiva que o autor recolheu no interior de Viamão.

16) Notas lingüístico-etnográficas sôbre a erva-mate no Rio Grande do Sul - Heinrich A. W. Bunse

O autor dedica explicativas notas linguístico-etnográficas à cultura, colheita e elaboração da erva-mate, pretendendo tornar conhecida uma rica e antiga terminologia e "fornecer ainda material de primeira mão, colhido em viagens de pesquisa na zona ervateira do Rio Grande do Sul, para futuros estudos comparativos em outras regiões produtoras de erva-mate, tanto no Brasil como da Argentina e do Paraguai”.

17) Alguns aspectos do linguajar gauchesco no Antônio Chimango - Niel Aquino Casses

O presente trabalho parcial é uma tentativa de explicação de alguns fatos linguísticos encontrados na poesia gauchesca, através do poema Antônio Chimango. Em suas conclusões, ele diz que não há dúvida de que a maior contribuição ao vocabulário gauchesco é de "procedência platina, castelhana e amerígena, como atestam vocábulos e expressões de uso quotidiano relativos aos apetrechos da faina campeira e ao sistema de vida pastorial”.

18) Algumas comparações comuns no linguajar gauchesco - Walter Spalding

A presente comunicação compõe-se de apenas 50 comparações a título de exemplificação do linguajar comum, diário do gaúcho, recolhida em alguns anos de convivência. 
Para o autor "Curioso é ainda notar-se que, nas comparações, o gaúcho raramente emprega a conjunção comparativa 'como'. Usa, de modo geral, em seu lugar 'que nem': AFIADO que nem língua de comadre em festança."

19) Regionalismos bahianos - Carlos Ott

Carlos Ott inicia sua comunicação dizendo que a Bahia apresenta um campo ideal para pesquisas folclóricas e linguísticas por ter sido uma das províncias brasileiras que mais recebeu imigrantes portugueses, além da influência africana e indígena. Cita o Mercado Modelo como um lugar ideal para estudos folclóricos e linguísticos. Dos regionalismos baianos enfatiza as rezas.

20) A obra dialectológica de José Leite de Vasconcellos: os trabalhos publicados e os inéditos $-(. . . . . . . . .)^{5}$

O autor apresenta os apontamentos de Dialetologia que Leite de Vasconcelos deixou inéditos e que esse autor ficou encarregado de elaborar e publicar. Refere que a Dialectologia, em Portugal, foi criada por Leite de Vasconcelos, a uns oitenta anos e, que o Congresso, por feliz coincidência, foi convocado para o dia do centenário de seu nascimento.

21) Uma fonte para o estudo do português do Brasil no séc. XIX - Hélcio Martins

Nesta comunicação, o autor divulga uma fonte documental que supunha não ser do conhecimento dos que estão investigando os falares brasileiros: as "palavras e frases que uma pessoa polida não pode usar", relacionadas pelo pernambucano Filipe Néri Colaço, em 1883. Nota-se um ajuste cada vez mais rigoroso ao uso culto da língua, já que o autor apresenta uma tábua de correção para as "pessoas polidas" do Recife, em fins do século XIX.

22) Pequeno esboço de um estudo da influência açoriana no linguajar do gaúcho brasileiro - Dante de Laytano

${ }^{5} \mathrm{Na}$ relação das apresentações na minuta dos Anais (ainda não publicados) não aparece o nome do comunicador. 
Trata-se de influências açorianas desde o século XVIII (no caudal imigratório), na linguagem do gaúcho, na fonética e no vocabulário. O autor comenta escritores gaúchos, nacionais e portugueses e seus trabalhos interessantes para a linguagem popular do Rio Grande do Sul.

23) Nota prévia sobre um brinquedo infantil (numa área catarinense) - Walter F. Piazza

A comunicação versa sobre notas preliminares a respeito de um inquérito que o autor realizou junto ao professorado primário do município de Brusque (Estado de Santa Catarina) no ano de 1958. Trata-se de um jogo infantil: "bolinha de gude" e as três denominações encontradas na cidade, sendo uma delas de origem alemã.

24) Algumas notas para o estudo do falar de Itaóca (município de Apiaí, São Paulo Antônio Lages de Magalhães

O roteiro da pesquisa segue o "Guia para estudos dialetológicos", de Serafim da Silva Neto: há notas sobre os informadores, a localidade, a terra, as medidas, as plantas, os animais, o homem, entre outras.

25) Contribuição para o estudo da linguagem dos salineiros de Cabo Frio - Sue Nogueira

Terminologia, descrição e vocabulário, informações fonéticas. O autor recolheu entrevistas com salineiros locais e com uns que vieram de Portugal, os quais falariam das diferenças estruturais entre as salinas do Brasil e Portugal, e da decorrente diferenciação de terminologias técnicas. O vocabulário é mais simples e prático do que o de Portugal.

26) Sincronia e diacronia nos sistemas vocálicos do crioulo caboverdeano - Herculano de Carvalho

Trabalho que se baseia no livro então "recente" de Baltasar Lopes da Silva, "O dialeto crioulo de Cabo Verde", Lisboa, 1957, e nas informações de dois alunos das ilhas, que representam dois padrões fonológicos distintos e aqui descritos: um de Barlavento e o outro de São Nicolau.

27) Dialeto de Macau - Silveira Bueno

Em 1957, Silveira Bueno foi coletar elementos do dialeto português que estava quase desaparecido em Macau, pelo uso quase exclusivo da língua chinesa. As notas 
apresentadas no Congresso são fruto das conversações conseguidas no asilo de velhos. "A pronúncia, o ritmo da frase assemelham-se muito ao falar rústico do Brasil, especialmente ao de São Paulo, porém muito mais atrasado e confuso que este". O autor acredita que "dentro de algumas décadas, o dialeto português de Macau estará completamente desaparecido".

28) Delimitação de regiões culturais no Brasil como sugestão para estudos de dialectologia - Manuel Diégues Júnior

As pesquisas tinham em vista contribuir para o preparo de um mapa cultural do Brasil. Nesta comunicação, o autor pretende mostrar as relações entre o critério de regiões culturais que ele adotou (o país faz parte de uma área maior, comum a Portugal) e a sua aplicação a estudos de dialetologia no Brasil. Este estudo, para o autor, deveria ser interdisciplinar, "em que a linguística merece lugar de destaque, participando das pesquisas que venham a oferecer a cada região sua verdadeira caracterização cultural, inclusive quanto a manifestações dialetais”.

29) Influência da língua portuguesa no dialeto falado na região colonial italiana do Rio Grande do Sul - Mário Gardelin

Interessante depoimento que o autor dá sobre os diversos dialetos italianos que vieram para o Rio Grande do Sul e que se tornaram um só (fizeram uma média geral) para que a comunicação se processasse melhor com a incorporação de palavras portuguesas, o que de imediato criou dificuldade. Segundo Gardelin "É difícil gravar a palavra em sua exata forma, sem recorrer-se ao dialeto original.”

30) Glossários de João Mendes da Silva - Lothar Hessel

Trata-se de precioso repositório vocabular que revela a vida e o linguajar da velha província de São Pedro, em três obras (romances), duas delas na linha indianista e a outra na literatura regional. Segundo o autor, "é uma contribuição a ser consultada futuramente quando se tratar do levantamento linguístico da língua portuguesa no Rio Grande do Sul, no século XIX”.

31) Dialectologia y estruturalismo diacrónico - Diego Catalán 
Diego Catalán trata da crise da Dialetologia, diante dos movimentos renovadores da Linguística surgida nas últimas décadas. "Os estudos não passam do descritivismo linguístico, cujo objeto de exame é a língua dos sujeitos rurais; não buscam renovação, mas imobilismo de seus cultivadores."

O autor faz uma forte crítica sobre a falta de originalidade dos jovens dialetólogos que apenas descrevem as falas locais. E recomenda o aproveitamento de algumas contribuições do Estruturalismo como meio de tirar a Dialectologia tradicional da estagnação a que a levaram os trabalhos puramente descritivos ou históricos, todos eles com seu caráter de "produtos em série".

Esta última comunicação dá uma mostra do pensamento inovador com relação ao rumo que necessitava tomar a Dialetologia.

Ao se ter acesso ao material do Congresso disponível, nota-se a presença de outros pesquisadores que possivelmente tenham apresentado trabalhos, mas que não estão entre as trinta e uma (31) comunicações, como a do Prof. Eugenio Coseriu. ${ }^{6}$

A notícia da realização do Congresso, em Porto Alegre, encontra-se na Revista Brasileira de Filologia, do mesmo ano.

\section{Recorte 2}

\section{º CONGRESSO BRASILEIRO DE ETNOGRAFIA E DIALECTOLOGIA}

Na Faculdade de Filosofia da Universidade de Pôrto Alegre realizou-se, de 1 a 7 de setembro, o $1^{\circ}$ Congresso Brasileiro de Etnografia e Dialectologia que teve a participação de numerosos Professores brasileiros e alguns mestres de fora, como Eugênio Asensio, I. S. Révah, Luís Filipe Lindlei Cintra, José Herculano de Carvalho, Manuel Alvar, Eugênio Coseriu, José Pedro Rona, J. M. Piel e Diego Catalan. Dirigiu o Congresso, como Presidente Executivo, o Professor Albino de Bem Veiga, Catedrático de Filologia Portuguêsa da Universidade do Rio Grande do Sul.

Fonte: revista brasileira de filologia (1958, p. 288-289)

\footnotetext{
${ }^{6}$ Altman (2017, p. 99) diz que Coseriu proferiu a comunicação sobre "Los conceptos de dialecto, nivel y estilo de lengua y el sentido próprio de la Dialectología", que foi publicada sob o título "Sentido y tareas de la Dialectología", México, Instituto de Investigaciones Filológicas, Centro De Lingüística Hispánica, Cadernos de Lingüística de la ALFAL oㅡ 8, 1982.
}

Revista Investigações, Recife, v. 32, n. 2, p. 419 - 435, Dezembro/2019 
No encerramento do Congresso, usou da palavra o Prof. Serafim da Silva Neto, de cujo discurso, transcrevo trechos do final.

\section{(...)}

"Este I Congresso de Dialetologia e Etnografia constituiu um grande passo no sentido de criar ambiente propício ao tão desejado e necessário Atlas Lingüístico-Etnográfico do Brasil."

(...)

"Ficamos conhecendo muitas coisas e podemos agora prosseguir com mais confiança."

Não nos iludimos quanto aos trabalhos e às dificuldades que nos esperam, pois sabemos que não é obra fácil, nem passível de se fazer apressadamente.

Nada, entretanto, nos deterá. Estou certo de que nenhum obstáculo, por mais penoso que seja, por mais sacrifícios que custem, nos impedirá de levar a cabo esta tarefa grandiosa e indispensável, que mais do que uma exigência de Filologia, é agora um imperativo patriótico.

Bem sabemos (e aqui o digo com as palavras de Fernando Pessoa) que "Deus quer, o homem sonha, a obra nasce!".

\section{Considerações finais}

Ao se ter conhecimento das diversas temáticas dos trabalhos apresentados, reconhece-se que o Congresso foi um momento "de auto-conhecimento da realidade e valorização das raízes brasileiras" (ALTENHOFEN, 2011, p.21). Tinha-se consciência de que tanto filólogos nacionais como estrangeiros que permaneciam algum tempo em nosso país haviam realizado muitos estudos em torno das transformações que nossa língua sofre em cada região e segundo características culturais. Cândido Jucá, em sua comunicação, conclamava a que trabalhos monográficos fossem dados a conhecer e publicados: "Se conhecerem monografias regionais, convém fazerem-nas sabidas". O que estava faltando era uma unidade que desse um panorama amplo e seguro do estado atual da língua portuguesa no Brasil, o que se conseguiria com a organização e feitura do Atlas.

Mesmo com todas as dificuldades apontadas no Congresso, os estudiosos não perderam o ânimo e decidiram pela elaboração de atlas regionais que futuramente comporiam o Atlas Linguístico-Etnográfico do Brasil. 


\section{Referências}

ALTENHOFEN, C.V. Os estudos de variação linguística e de línguas em contato com o português: raízes históricas da pesquisa no Instituto de Letras da UFRGS. In: MITTMANN, S.; SANSEVERINO, A.M.V. (orgs.). Trilhas de investigação: a pesquisa no I. L. em sua diversidade construtiva. Porto Alegre: Instituto de Letras/UFRGS, 2011. p. 1731.

ALTMAN, C. Eugenio Coseriu entre a Filologia e a Linguística Brasileiras (1950-1963). Revista de la Academia Nacional de Letras: Uruguay, n. 13, 2017. p. 97 a 117.

BEM VEIGA, A. de. Discurso de abertura do I Congresso Brasileiro de Dialectologia e Etnografia. Manuscritos dos Anais do I Congresso Brasileiro de Dialectologia e Etnografia, 1958, 4fl. Localizado em: Acervo dos Projetos ALERS / ALMA-H, Instituto de Letras, Universidade Federal do Rio Grande do Sul.

CASTILHO, A. de. Rumos da Dialetologia Portuguesa. ALFA: Marília, v.18-19, 1972-3· p. $115-153$.

COMISSÃO CENTRAL ORGANIZADORA do I Congresso Brasileiro de Dialetologia e Etnografia. Primeira Circular. Porto Alegre: Faculdade de Filosofia da UFRGS, 1958.

MARIANI, B.; MEDEIROS, V. G. de. Notícias de duas pesquisas: idéias linguísticas e o governo JK. Veredas on line, 1/2007, p. 128-144. PPG Linguística/UFJF, Juiz de Fora.

PEREIRA, C. da C. A evolução dos estudos dialectológicos no Brasil. In:

PEREIRA, P. R. Miscelânea de estudos linguísticos, filológicos e literários in Memorian Celso Cunha. Rio de Janeiro: Nova Fronteira, 1995. p. 349-368.

REVISTA BRASILEIRA DE FILOLOGIA. Rio de Janeiro, v. 3, tomo o2, dez. $1957 \mathrm{~b}$. . Rio de Janeiro, v. 4, tomos o1-02, 1958.

\footnotetext{
* Professora Associado IV com Doutorado em Letras pela PUCRS (2000) e PósDoutorado em Letras pela UFRGS (2018). É líder do GEFF (Grupo de Estudo em Fonética e Fonologia), da Fundação Universidade Federal do Rio Grande. Atua nas áreas de Fonologia, Dialetologia e Sociolinguística.
} 